\title{
Breast Cancer in Inner Mongolia 2009-2011
}

\author{
Qin Li', Maolin Du², Kepeng Xin², Rong Liu², Yun Li², Wuyuntana Li², Xiong Su², Juan Sun ${ }^{2 *}$ \\ ${ }^{1}$ Inner Mongolia Medical University Affiliated People's Hospital, Hohhot, China \\ ${ }^{2}$ Inner Mongolia Medical University, Hohhot, China \\ Email: *nsunjuan@aliyun.com
}

Received 3 February 2014; revised 3 March 2014; accepted 10 March 2014

Copyright (C) 2014 by authors and Scientific Research Publishing Inc.

This work is licensed under the Creative Commons Attribution International License (CC BY).

http://creativecommons.org/licenses/by/4.0/

(c) (i) Open Access

\section{Abstract}

The aim of this study was to determine the mortality rate and the burden of breast cancers among residents of Inner Mongolia. We analyzed mortality data reported by the Death Registry System from 2009 to 2011. The age-specific mortality of breast cancer was close to female cancer in 25 to 35 years group. Regional distribution of breast cancer was not significant difference $(p=0.36)$. The women who were employed, married and living in rural areas were more likely to die of breast cancer. Over the period 2009 through 2011, the elimination of deaths from breast cancer resulted in increased life expectancy of 0.15 years. Mortality due to breast cancers is substantially greater among the younger women. Further, the mortality rate associated with breast cancers is greater for employed and married women than those unemployed and single women. Therefore, in Inner Mongolia, breast cancers appear to pose a greater mortality risk for young, employed and married women.

\section{Keywords}

Breast Cancer, Mortality Rate, Life Expectancy

\section{Introduction}

"Breast cancer is the leading cause of cancer death in female worldwide, accounting for 14\% $(458,400)$ of the total cancer deaths in 2008 [1]." "Breast cancer is the most commonly diagnosed cancer and the second-leading cause of cancer related deaths among women in the US [2]." "It is also the most common tumor in European women and is the first cause of death by cancer in females [3]."

Cancer is a major public health problem in China. Based on reports from the Ministry of Health [4]; it is the second cause of death in China. "In China, breast cancer is the fifth most common cause of death for Chinese women and the mortality was 10.2 per 100,000 [4]." "Breast cancer mortality has been on the increase until re-

*Corresponding author.

How to cite this paper: Li, Q., et al. (2014) Breast Cancer in Inner Mongolia 2009-2011. Open Journal of Epidemiology, 4, 63-68. http://dx.doi.org/10.4236/ojepi.2014.42011 
cently in China [5]." "It was 9.14 per 100,000 and accounted for 6.86\% of all cancer deaths in females in 2006 [6], however, it was 10.24 per 100,000 and accounted for 7.54\% in 2009 [4].”

Hence, it is necessary and important to get accurate projections of breast cancer mortality. However, there were few studies for breast cancer mortality in Inner Mongolia. The aim of this study is to assess the breast cancer mortality and its burden in Inner Mongolia. The data covered a larger population and reflected the most recent and accurate estimate of cancer burden in Inner Mongolia.

\section{Materials and Methods}

Breast cancer and female cancer death data were obtained from the Death Registry System, maintained by the Inner Mongolia Centers for Disease Control and Prevention (CDC). The five monitoring points from the death registry system are Muslims District in Hohhot City, Linhe District in Bayannur City, Sonid Youqi in Xilingol League, Bairin Youqi in Chifeng City and Kailu County in Tongliao City, respectively. The five monitoring points are located in the eastern, middle and western regions in Inner Mongolia. Three regions are divided according to their geographical location, historical evolution, traditional lifestyle, as well as some provisions for policy laws.

The death database included information on primary cause of death, death date, sex, and age. The cause of death was coded according to the International Classification of Disease-10th Revision (ICD-10). The ICD-10 codes were grouped in this study into breast cancer (C50) and malignant neoplasms of female genital organs (C51-C57). Breast cancer and malignant neoplasms of female genital organs are called female cancer.

The annual midyear population figures in 2009-2011 were obtained from the CDC of Inner Mongolia to calculate age-specific mortality and annual mortality of each region per 100,000 women. Occupational status, marital status and urban/rural area were chosen as the indicators to assess the demographic characteristics of breast cancer and female cancer mortality. The death number and percentage of breast cancer and female cancer were calculated for five monitoring points.

Potential years of life lost (PYLL) are used to emphasize premature mortality by estimating the average time a person would have lived had he or she not died prematurely. We used PYLL to measure the contribution of changes in breast cancer and female cancer mortality on overall changes in life expectancy during the period 2009-2011.

Microsoft Excel software and SPSS 13.0 statistical software were used for data management and analysis. The $\chi^{2}$ test was used to assess differences in rates, and a significance level of 0.05 was used.

\section{Results}

The age-specific mortality from 2009 to 2011 for breast cancer and female cancer are shown in Figure 1. The breast cancer accounted for three-fourths of the female cancer from 25 to 35 years. Breast cancer mortality was a half of the female cancer mortality, although the mortality of breast cancer decreased after 40 . The age-specific mortality trends were similar between breast cancer and female cancer.

Figure 2 shows the region trend of mortality for breast cancer and female cancer. There were differences for breast cancer mortality between eastern region and Midwest regions, whereas less differences between middle region and western region [Figure 2(a)]. A gradual and steady increasing trend in female cancer mortality was observed in three regions from 2009 to 2010. This trend was not observed in 2011 [Figure 2(b)]. In three regions, the mortality trend for both breast cancer and female cancer was decreased from 2009 to 2011, except breast cancer in 2009. There was no significant difference in death distribution both breast cancer $(p=0.36)$ and female cancer $(p=0.19)$ in three regions.

Table 1 shows the percentage of female cancer and breast cancer deaths for occupational status, married status and resident areas. Most deaths were married. Employment women were 3 times more than unemployment women. Although rural areas were higher than urban areas, the difference was a little.

Figure 3 displays the PYLL associated with breast cancer and female cancer in Inner Mongolia from 2009 to 2011. The elimination of deaths from female cancer and breast cancer resulted in increased life expectancy of 0.31 and 0.15 years respectively. The impact of the elimination of breast cancer remained relatively stable under 30 in women and relative years of life lost associated with female cancer is much 2.1 times than breast cancer. After 35, relative years of life lost associated with female cancer and breast cancer decreased rapidly, but the speed was relatively faster in female cancer. 


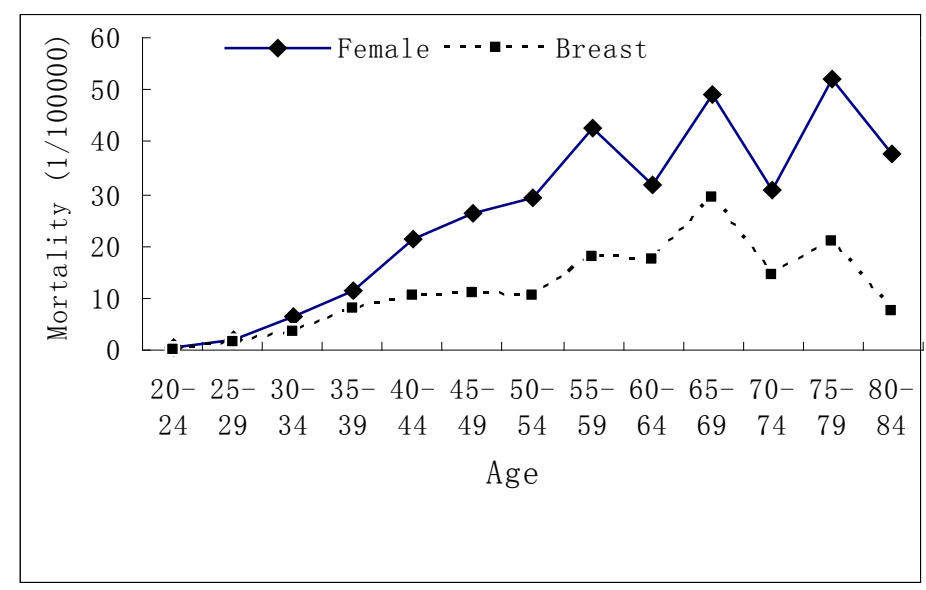

Figure 1. Age-specific mortality from female and breast cancer in five monitoring poins.

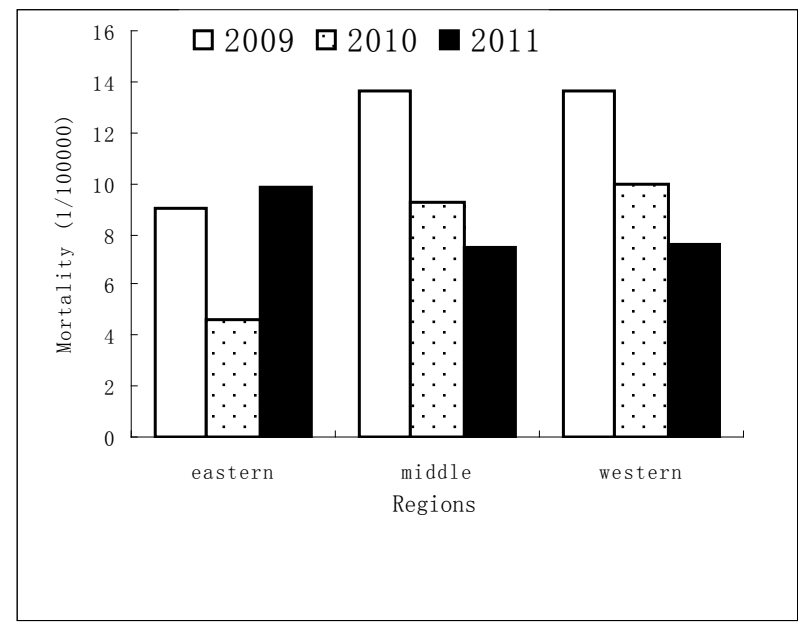

(a)

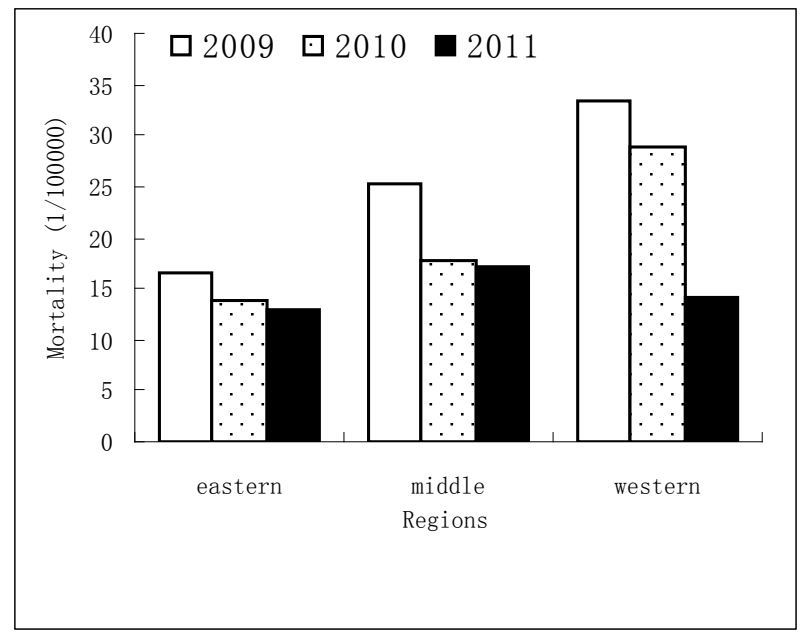

(b)

Figure 2. (a) The mortality of breast cancer in eastern, middle and western of Inner Mongolia. (b) The mortality of female cancer in eastern, middle and western of Inner Mongolia. 


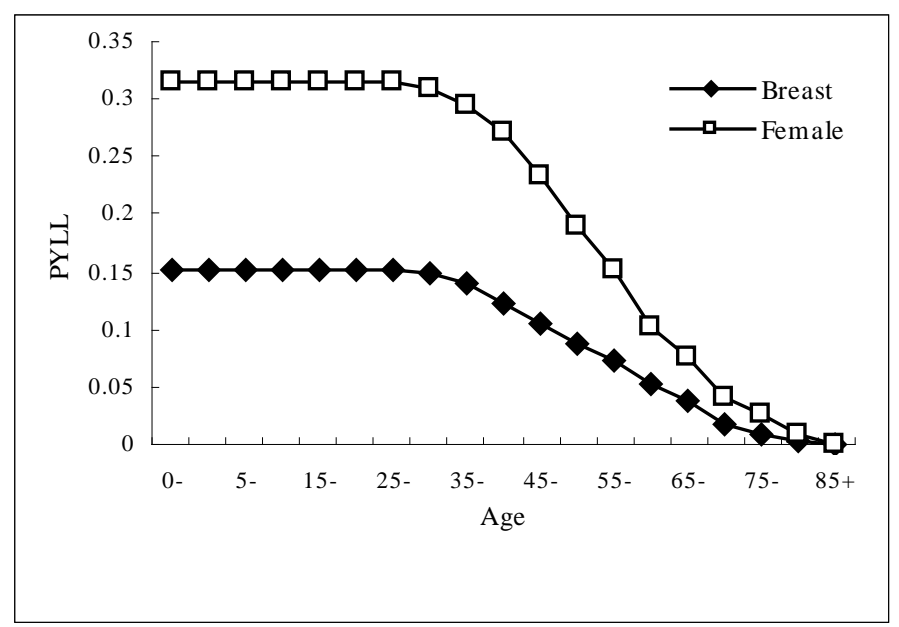

Figure 3. The PYLL of female cancer and breast cancer in Inner Mongolia, 2009-2011.

Table 1. Percentage of breast cancer and female cancer in monitoring points.

\begin{tabular}{|c|c|c|c|c|}
\hline & \multicolumn{2}{|c|}{ Breast cancer } & \multirow{2}{*}{$\begin{array}{c}\text { Female cancer } \\
\text { n }=335\end{array}$} & \multirow[b]{2}{*}{$\%$} \\
\hline & $\mathrm{n}=158$ & $\%$ & & \\
\hline \multicolumn{5}{|c|}{ Occupational status } \\
\hline Employed & 119 & 75.3 & 254 & 75.8 \\
\hline Unemployed & 39 & 24.7 & 81 & 24.2 \\
\hline \multicolumn{5}{|c|}{ Married status } \\
\hline Unmarried & 2 & 1.3 & 3 & 0.9 \\
\hline Divorce & 0 & 0.0 & 1 & 0.3 \\
\hline Widowed & 13 & 8.2 & 25 & 7.5 \\
\hline Married & 143 & 90.5 & 303 & 90.4 \\
\hline Unknown & 0 & 0.0 & 3 & 0.9 \\
\hline \multicolumn{5}{|l|}{ Area } \\
\hline Urban & 74 & 46.8 & 164 & 49 \\
\hline Rural & 84 & 53.2 & 171 & 51 \\
\hline
\end{tabular}

\section{Discussion}

In this study, we calculated breast cancer mortality in order to identify the magnitude of breast cancer in female cancer in Inner Mongolia. Breast cancer mortality ranked the first in female cancer mortality from 2009 to 2011. The result was consistent with the report from National Central Cancer Registry (NCCR) of China [4].

Age-specific mortality showed that breast cancer has a higher proportion of deaths before 35 years age group compared to female cancer. The breast cancer mortality increased with ages before 65 years age group. The mortality began decreasing in 70 years age group. Our results are different from other East Asian studies [7]. The mortality increased with ages in these regions. The increasing trend was rapid in young and steady in old people. The highest mortality was in the highest age groups. The discrepancies may reflect differences in the detection and management of breast cancer. Some studies showed breast cancer screening reduces breast cancer mortality [8]. In Inner Mongolia, lack of breast cancer screening programs may be one of reasons for young 
people with higher mortality. In Japan, however, young people with lower breast cancer mortality are attributed to high rate of breast cancer screening.

The findings of our study suggest that breast cancer was decreasing over the time, except eastern region in 2011. One possible explanation for the role of region may be the effect of economic levels. Recently, there have been suggestions that female breast cancer mortality was higher in the high economic levels than in the low economic levels [9]. In Inner Mongolia, the western region has the highest economic levels, followed by the middle region, and eastern region is lower than these regions. Our data is in agreement with this trend. However, this trend requires further research.

The findings of our study show that women who were in employment were more likely to die of breast cancer than those unemployed women. The result is consistent with other studies. Employed women have high levels of strain for their job and family than the unemployed. Some studies showed that high levels of strain were as- sociated with a slight increase in the risk of breast cancer [10]. Many employed women tend to postpone the age of the first birth. Older age at first birth increases the risk for breast cancer [11].

The findings of our study show that the proportion of women with breast cancer deaths who were married was more than other women. Married may be one risk factor for breast cancer in Inner Mongolia. With regard to the findings from the present study, one may argue that the relatively high proportion of married breast cancer deaths is most likely due a to a married population structure. Evidence from the Norwegian women suggests that, breast cancer was found to be decreased among divorced women [12]. Similarly, divorced women had a decreased risk of breast cancer in Swedish women [13].

The proportion of breast cancer mortality in rural areas was slightly higher than urban areas. In China, this proportion in rural areas (4.92\%) was lower than that in urban areas (9.47\%) in 2006 [6]. The results are opposite with our findings. The difference between rural areas and urban areas may due to the absence of breast cancer screening programs and health education in rural areas, whereas such programs are fully or partly implemented in the majority of urban areas in Inner Mongolia.

The findings of our study show that PYLL of female cancer and breast cancer were high before 30. The result is different from our previous study for Japanese at the end of the last century [14]. Our previous study showed that PYLL of breast cancer were high before 40, and it decreased rapidly after 45. It is indicated that the death age of breast cancer was earlier than Japanese women. Some risk factors that associated with the developed countries such as higher economic income, higher education and screening programs, can explain the reason why the higher age of death in these countries.

In the present study, we report the characteristics of breast cancer between five monitoring points located in three different regions in Inner Mongolia. The mortality of breast cancer in the three regions increased with age. There is not a significant difference in death distribution in the three regions. The deaths of breast cancer and female cancer are more likely to be employed women and married women. The death of breast cancer for young women is more serious. Further studies are needed to assess more recent trends in the mortality of breast cancer as well as the respective roles of genetic and environmental factors of breast cancer in Inner Mongolia.

\section{Supportive Foundations}

It is supported by Inner Mongolia Autonomous Region Colleges and Universities of Science and Technology Research Projects, No. NJZY13415, Inner Mongolia Medical University Technology million project, No. NY2011BW006, Natural Science Foundation of Inner Mongolia in China (2013MS1124).

\section{References}

[1] Jemal, A., Bray, F., Center, M.M., Ferlay, J., Ward, E. and Forman, D. (2011) Global Cancer Statistics. CA: A Cancer Journal for Clinicians, 61, 69-90. http://dx.doi.org/10.3322/caac.20107

[2] Siegel, R., Naishadham, D. and Jemal, A. (2013) Cancer Statistics, 2013. CA: A Cancer Journal for Clinicians, 63, 1130. http://dx.doi.org/10.3322/caac.21166

[3] Izquierdo, A., Gispert, R., Saladie, F. and Espinas, J.A. (2008) Analysis of Cancer Incidence, Survival and Mortality According to the Main Tumoral Localizations, 1985-2019: Breast Cancer. Medicina Clínica, 131, 50-52. http://dx.doi.org/10.1016/S0025-7753(08)76433-9

[4] Chen, W., Zheng, R., Zhang, S., Zhao, P., Li, G., Wu, L. and He, J. (2013) The Incidences and Mortalities of Major Cancers in China, 2009. Chinese Journal of Cancer, 32,106-112. http://dx.doi.org/10.5732/cjc.013.10018 
[5] Yang, L., Parkin, D.M., Li, L.D., Chen, Y.D. and Bray, F. (2004) Estimation and Projection of the National Profile of Cancer Mortality in China: 1991-2005. British Journal of Cancer, 90, 2157-2166. http://dx.doi.org/10.1038/sj.bjc.6601813

[6] Chen, W.Q., Zhang, S.W., Zou, X.N. and Zhao, P. (2011) Cancer Incidence and Mortality in China, 2006. Chinese Journal of Cancer Research, 23, 3-9. http://dx.doi.org/10.1007/s11670-011-0003-9

[7] Shin, H.-R., Boniol, M., Joubert, C., Hery, C., Haukka, J., Autier, P., Nishino, Y., Sobue, T., Chen, C.-J., You, S.-L., Ahn, S.H., Jung, K.W., Law, S.C.-K., Mang, O. and Chia, K.-S. (2010) Secular Trends in Breast Cancer Mortality in Five East Asian Populations: Hong Kong, Japan, Korea, Singapore and Taiwan. Cancer Science, 101, 1241-1246. http://dx.doi.org/10.1111/j.1349-7006.2010.01519.x

[8] Nelson, H.D., Tyne, K., Naik, A., Bougatsos, C., Chan, B.K. and Humphrey, L. (2009) Screening for Breast Cancer: An Update for the US Preventive Services Task Force. Annals of Internal Medicine, 151, 727-737, W237-W742. http://dx.doi.org/10.7326/0003-4819-151-10-200911170-00009

[9] Belon, A.P., Barros, M.B. and Marin-Leon, L. (2012) Mortality among Adults: Gender and Socioeconomic Differences in a Brazilian City. BMC Public Health, 12, 39. http://dx.doi.org/10.1186/1471-2458-12-39

[10] Kuper, H., Yang, L., Theorell, T. and Weiderpass, E. (2007) Job Strain and Risk of Breast Cancer. Epidemiology, 18, 764-768. http://dx.doi.org/10.1097/EDE.0b013e318142c534

[11] Merrill, R.M., Fugal, S., Novilla, L.B. and Raphael, M.C. (2005) Cancer Risk Associated with Early and Late Maternal Age at First Birth. Gynecologic Oncology, 96, 583-593. http://dx.doi.org/10.1016/j.ygyno.2004.11.038

[12] Bjorge, T. and Kravdal, O. (1996) Reproductive Variables and Risk of Uterine Cervical Cancer in Norwegian Registry Data. Cancer Causes Control, 7, 351-357. http://dx.doi.org/10.1007/BF00052941

[13] Hemminki, K. and Li, X. (2003) Lifestyle and Cancer: Effect of Widowhood and Divorce. Cancer Epidemiology, Biomarkers \& Prevention, 12, 899-904.

[14] Kono, A., Misumi, J. and Misumi, J. (2005) The Time Trend of Breast Cancer Mortality in Japan. Archives of Gynecology and Obstetrics, 272, 187-190. http://dx.doi.org/10.1007/s00404-004-0719-6 